\title{
Influence of carbon content and nitrogen vacancies on the bonding structure and mechanical performance of graphite-like $\mathrm{BC}_{x} \mathrm{~N}$ thin films
}

\author{
Ignacio Carettia) and Ignacio Jiménez \\ Instituto de Ciencia de Materiales de Madrid (ICMM-CSIC), Campus de Cantoblanco, 28049 Madrid, Spain
}

(Received 9 February 2012; accepted 22 August 2012; published online 26 September 2012)

\begin{abstract}
X-ray absorption near edge structure (XANES) was used to investigate two sets of graphite-like $\mathrm{BC}_{\mathrm{x}} \mathrm{N}$ thin films with similar $\mathrm{B}: \mathrm{C}: \mathrm{N}$ ratios but different amounts of nitrogen vacancies, which become oxygen-filled in the surface-most region. The two sets of samples were grown on $\mathrm{Si}$ (100) at room temperature by ion beam assisted deposition using two different ion/atom ratios. Nitrogen vacancy defects were detected in the B1s XANES spectra due to an oxygen decoration mechanism taking place at the film surface, which is correctly described by a core-level shift model. Analysis of the O1s XANES spectra showed two different types of oxygen incorporation in the samples under study. The tribomechanical properties of the $\mathrm{BC}_{\mathrm{x}} \mathrm{N}$ samples were tested by the pin-on-disk technique, revealing the substantial role played by both the carbon intake in the hexagonal BCN planes and the concentration of nitrogen vacancies generated during the growth. (C) 2012 American Institute of Physics. [http://dx.doi.org/10.1063/1.4752757]
\end{abstract}

\section{INTRODUCTION}

New covalent boron-carbon-nitrogen (B-C-N) materials and related nanostructures occupy a privileged position amongst candidates for high-temperature optical, electrical, and mechanical applications. ${ }^{1}$ In particular, ternary boron carbonitride $\left(\mathrm{BC}_{\mathrm{x}} \mathrm{N}_{\mathrm{y}}\right)$ solid solutions have attracted considerable interest in the last decades as alternatives to increase the performance of elemental (graphite, diamond, $\alpha-r h$ boron, etc.) and binary ( $h$ - $\mathrm{BN}, c-\mathrm{BN}, \mathrm{B}_{4} \mathrm{C}, h-\mathrm{CN}_{\mathrm{x}}$, etc.) phases of the $\mathrm{B}-\mathrm{C}-\mathrm{N}$ system. Due to its high technological potential, $\mathrm{BC}_{\mathrm{x}} \mathrm{N}_{\mathrm{y}}$ thin films have been produced by several chemical ${ }^{2-13}$ and physical vapour ${ }^{14-24}$ deposition methods. Up to now, among other possible compositions and structures, ternary compounds with hexagonal phase and a $\mathrm{BC}_{\mathrm{x}} \mathrm{N}$ stoichiometry, i.e., $h-\mathrm{BC}_{\mathrm{x}} \mathrm{N}$, have been reported, ${ }^{2-4,15,16,22,23}$ which are interesting for tunable band gap optoelectronic devices ${ }^{25}$ or as protective coatings. ${ }^{22}$

One of the key issues with regard to $\mathrm{BC}_{\mathrm{x}} \mathrm{N}_{\mathrm{y}}$ layered compounds is the identification of their structure, since their metastable character usually results in the formation of lowordered materials (either amorphous or with nanometric grain size) and a tendency to phase segregation. ${ }^{18,26-29}$

Besides, similar to the case of $h$-BN materials, the occurrence of defects is a fundamental concern in $h-\mathrm{BC}_{\mathrm{x}} \mathrm{N}$ compounds. Specifically, nitrogen vacancies and interstitials have been regularly observed in the X-ray absorption near edge structure (XANES) spectra of $h$-BN films and nanostructures. ${ }^{30-32}$ In this sense, we have recently also reported the existence of nitrogen-vacancy defects in $h-\mathrm{BC}_{\mathrm{x}} \mathrm{N}$, which are detected by XANES analysis through an oxygen decoration process at the surface of the material. ${ }^{32}$ In this work, we analyse in detail the influence of the carbon content and the concentration of $\mathrm{N}$ vacancies on the bonding structure and mechanical resistance of $\mathrm{BC}_{\mathrm{x}} \mathrm{N}$ coatings grown by ion beam

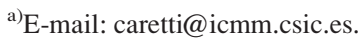

assisted deposition (IBAD) at room temperature on $\mathrm{Si}(100)$ substrates.

\section{EXPERIMENTAL}

The IBAD system was equipped with separated sources for $\mathrm{B}, \mathrm{C}$, and $\mathrm{N}$ elements. $\mathrm{B}$ and $\mathrm{C}$ were e-beam evaporated and nitrogen was provided as ions of $500 \mathrm{eV}$ from a Kaufman ion gun. We prepared two sets of samples labelled as $\mathrm{BC}_{\mathrm{x}} \mathrm{N}-(\mathrm{a})$ and $\mathrm{BC}_{\mathrm{x}} \mathrm{N}-(\mathrm{b})$, which have the same $\mathrm{B}: \mathrm{C}: \mathrm{N}$ composition but different concentration of N-vacancy defects. We anticipate here that series (b) contains a larger fraction of these defects than series (a), as will be discussed later on.

According to our previous results on binary $\mathrm{B}_{\mathrm{x}} \mathrm{N}_{1-\mathrm{x}}$ compounds grown by $\mathrm{IBAD},{ }^{33}$ films with a $\mathrm{B}: \mathrm{N} \sim 1: 1$ composition ratio are obtained for a wide range of impinging $\Phi_{\mathrm{B}} / \Phi_{\mathrm{N}}$ atomic fluxes between 1 and 3, although containing a different concentration of $\mathrm{N}$ vacancies. The same applies to $\mathrm{BCN}$ compounds, since we can vary the ion dose without affecting the $\mathrm{B}: \mathrm{C}: \mathrm{N}$ composition of the films, but changing the defect concentration. $\mathrm{BC}_{\mathrm{x}} \mathrm{N}-(\mathrm{a})$ and $\mathrm{BC}_{\mathrm{x}} \mathrm{N}-(\mathrm{b})$ coatings were deposited using fixed $\Phi_{\mathrm{B}} / \Phi_{\mathrm{N}} \sim 1.6$ and $\Phi_{\mathrm{B}} / \Phi_{\mathrm{N}} \sim 1.0$ ratios, respectively, and varying the $\mathrm{C}$ evaporation flux. All films were grown in the same experimental conditions reported in Ref. 34.

The overall film composition was evaluated for all samples by $\mathrm{x}$-ray emission energy dispersion analysis (XEDS) in a Philips XL30 ESEM scanning electron microscope equipped with an $\operatorname{EDAX}^{\circledR}$ superultrathin window (superUTW) with a $\mathrm{Si}(\mathrm{Li})$ detector. The composition was computed using the method described in Ref. 35 for the microanalysis of BCNObased thin film materials.

For the analysis of the structure, conventional diffraction techniques provide in general little information due to the lack of long range order in $\mathrm{BC}_{\mathrm{x}} \mathrm{N}_{\mathrm{y}}$ coatings, as well as the low and similar scattering amplitudes of B, C, and N. However, X-ray absorption near edge structure (XANES) appears as one the most informative spectroscopies for the study of 
$\mathrm{BC}_{\mathrm{x}} \mathrm{N}_{\mathrm{y}}$ coatings, since it provides us with element, site and local structure specific information by monitoring the electron transitions from the $1 s$ core-levels to the unoccupied conduction states. Whereas electron energy loss spectroscopy (EELS) gives analogous information to XANES with a higher spatial resolution, it lacks in general the energy resolution needed to resolve defect related transitions. The XANES experiments were conducted at beamline PM4 of BESSY using the SurICat endstation. The data were acquired in the total electron yield mode as explained in previous work. $^{15}$

The film composition was determined both with surface and bulk sensitivity by XANES and XEDS, respectively. The samples considered in the present study exhibit similar $\mathrm{B}: \mathrm{C}: \mathrm{N}$ ratios by both techniques, within a maximum discrepancy of 5 at. \% for each element, but a different $\mathrm{O}$ content. XEDS analysis yields an oxygen content in the bulk up to $\sim 1$ at. $\%$ for both $\mathrm{BC}_{\mathrm{x}} \mathrm{N}-(\mathrm{a})$ and $\mathrm{BC}_{\mathrm{x}} \mathrm{N}-(\mathrm{b})$ sample series, while the surface oxygen concentration measured by XANES varies between $\sim 2$ and 30 at. $\%$ and depends on the amount of defects. This issue will be discussed later in detail.

\section{RESULTS AND DISCUSSION}

Figs. 1 and 2 show the $\mathrm{B} 1 s, \mathrm{C} 1 s$, and N1s XANES spectra of selected $\mathrm{BC}_{x} \mathrm{~N}-(\mathrm{a})$ and $\mathrm{BC}_{x} \mathrm{~N}-(\mathrm{b})$ films for increasing $\mathrm{C}$ at. $\%$. Note that the B:C:N compositions of series (a) and (b) are similar, but their XANES spectra are different owing to their defect concentration. The presence of $\pi^{*}$ and $\sigma^{*}$ state regions in all XANES spectra indicate the hexagonal bonding structure of these $\mathrm{BC}_{x} \mathrm{~N}$ films. The reference spectra of $h-\mathrm{BN}, c-\mathrm{BN}$, $\mathrm{B}_{2} \mathrm{O}_{3}, \mathrm{~B}_{4} \mathrm{C}$, diamond, graphite, and IBAD grown $\mathrm{CN}_{x}$ are included at the bottom of each panel, corresponding to the most common chemical environments within the B-C-N system.

\section{A. Boron and oxygen $1 \mathrm{~s}$ core-level edges}

For both (a) and (b) set of samples, the B1s core-level reveals a downwards energy shift of the $\sigma^{*}$ edge from
197.2 $\mathrm{eV}$ to $195.0 \mathrm{eV}$ with increasing $\mathrm{C}$ concentration. This observation points to a decrease of the ionization potential, and hence an increase of the bond length towards intermediate distances between pure $\mathrm{sp}^{2}$ (e.g., $0.145 \mathrm{~nm}$ in $h$-BN) and pure $\mathrm{sp}^{3}$ (e.g., $0.157 \mathrm{~nm}$ in $c$-BN) hybridizations (see B1s $\sigma^{*}$ edge of reference materials). Such a change is consistent with the amorphization of the graphite-like structure as carbon is incorporated in the films.

In the $\mathrm{B} 1 s \pi^{*}$ region, we observe a tail of states between $189.5 \mathrm{eV}-191.5 \mathrm{eV}$ and four well-resolved excitonic peaks at higher photon energies. Our previous work, on $\mathrm{BC}_{x} \mathrm{~N}$ point defects ${ }^{32}$ demonstrated that these $\mathrm{B}\left(1 s \rightarrow \pi^{*}\right)$ features can be properly described by means of a core-level shift model, which considers the possible $\mathrm{sp}^{2}$ environments of $\mathrm{B}$ bound to $\mathrm{N}, \mathrm{C}$, and $\mathrm{O}$, the latter arising from oxygen decoration of the nitrogen vacancies when the samples are exposed to air. The model predicts 7 excitonic peaks $\left(B_{0}-B_{6}\right)$, corresponding to 10 different bonding environments of tricoordinated $\mathrm{B}$ in the hexagonal network, three of which almost coincide in energy, as indicated in Table I. According to this, a maximum of 7 Gaussian curves is needed for the deconvolution of the $\mathrm{B} 1 s \pi^{*}$ states of $\mathrm{BC}_{x} \mathrm{~N}-(\mathrm{a})$ and $\mathrm{BC}_{x} \mathrm{~N}-(\mathrm{b})$ compounds. This is shown in Fig. 3 for several $\mathrm{C}$ concentrations in the films. Table I shows a good agreement between the apparent energies of these peaks and the ones predicted by the abovementioned model.

We observe that carbon incorporation is followed by an increase of $\mathrm{B}$ features related to $\mathrm{B}-\mathrm{C}$ coordination, which appear below $192 \mathrm{eV}\left(B_{0}-B_{2}\right)$, plus a clear broadening and loss of resolution of the B1s $\pi^{*}$ spectra. As confirmed by our previous transmission electron microscopy (TEM) studies, ${ }^{23}$ these changes imply a reduction of the short-range order and an amorphization of the material due to $\mathrm{C}$ inclusion, up to the formation of a completely amorphous BCN compound.

In general, for the same $\mathrm{C}$ concentration, the intensity of $B_{4}-B_{6}$ peaks is higher in $\mathrm{BC}_{x} \mathrm{~N}-(\mathrm{b})$ than $\mathrm{BC}_{x} \mathrm{~N}-$ (a) films. Since these peaks are related to oxygen decorated nitrogen vacancies upon exposure to air, the overall concentration of

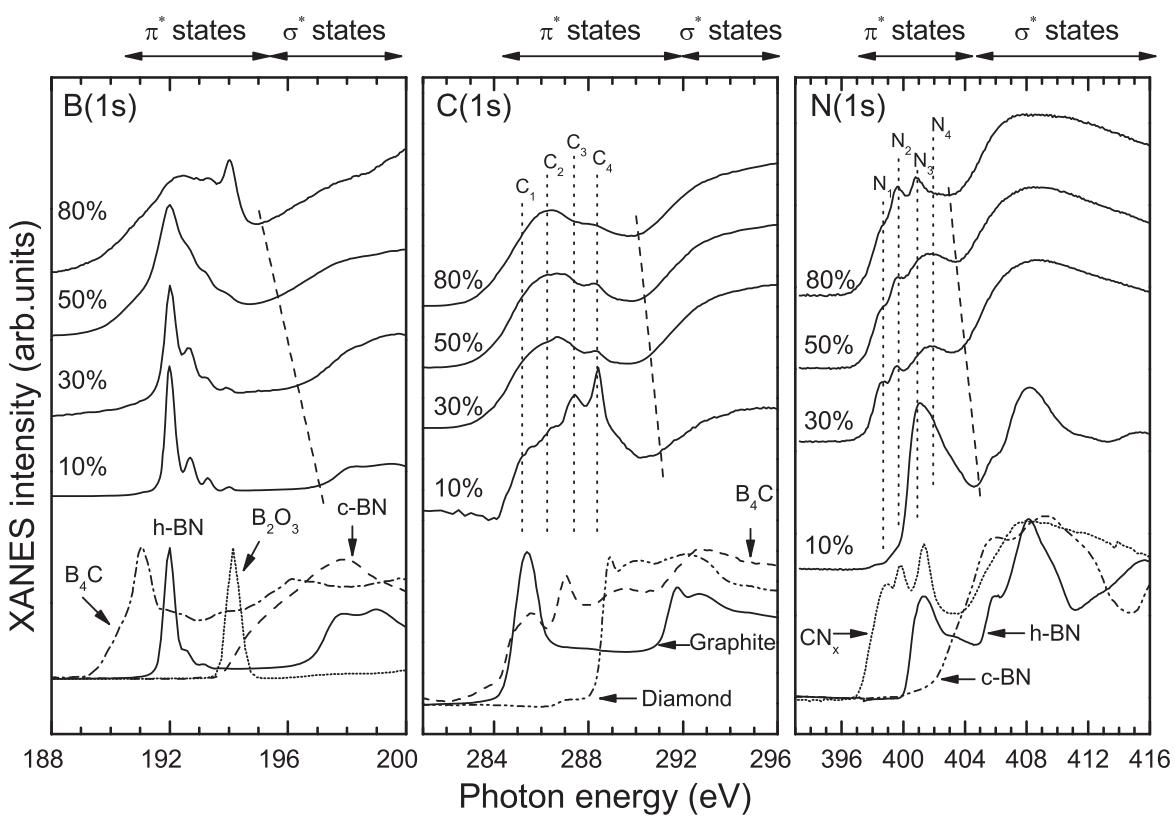

FIG. 1. B $1 s, \mathrm{C} 1 s$ and N1s XANES spectra of the low defective $\mathrm{BC}_{\mathrm{x}} \mathrm{N}$-(a) series together with the $h$ - $\mathrm{BN}, c$ - $\mathrm{BN}, \mathrm{CN}_{\mathrm{x}}, \mathrm{B}_{4} \mathrm{C}, \mathrm{B}_{2} \mathrm{O}_{3}$, graphite, and diamond references. 

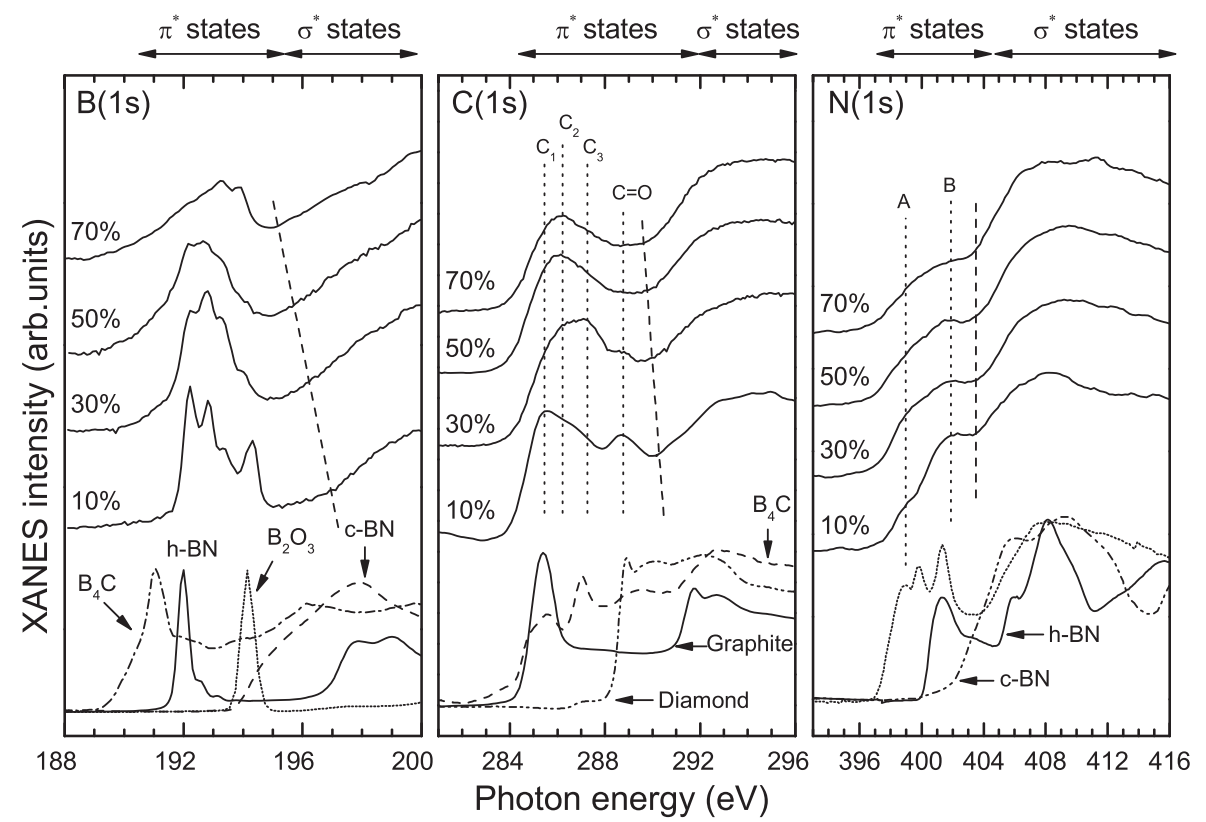

FIG. 2. B $1 s, \mathrm{C} 1 s$ and N1s XANES spectra of the high defective $\mathrm{BC}_{\mathrm{x}} \mathrm{N}-(\mathrm{b})$ series together with the $h$ - $\mathrm{BN}, c-\mathrm{BN}, \mathrm{CN}_{\mathrm{x}}, \mathrm{B}_{4} \mathrm{C}, \mathrm{B}_{2} \mathrm{O}_{3}$, graphite, and diamond references.

nitrogen vacancies is significantly larger in $\mathrm{BC}_{x} \mathrm{~N}-(\mathrm{b})$, up to $\sim 40 \%$ of atomic sites. ${ }^{32}$ Notice that the B1s XANES spectra of $\mathrm{BC}_{x} \mathrm{~N}$-(a) films exhibit a dominant intensity of peak $B_{3}$ up to a $\mathrm{C}$ content of 65 at. $\%$ (i.e., a $\mathrm{BC}_{4} \mathrm{~N}$ composition), what suggests a higher hexagonal order than series (b). For larger $\mathrm{C}$ concentrations the $\mathrm{B} 1 s$ signals from both series (a) and (b) are rather similar, with a broad band centered at $192 \mathrm{eV}$, composed of a manifold of unresolved peaks, and a distinctive peak $B_{6}$ (corresponding to a boron atom surrounded by 3 oxygen substituted $\mathrm{N}$-vacancies) that rises significantly. This bonding configuration corresponds to an amorphous material based on a distorted hexagonal network, with a large fraction of boron atoms in incomplete coordination due to the presence of nitrogen vacancies. Thus, even though both sets of samples have the same B:C:N composition, the higher ionatom ratio used for the deposition of $\mathrm{BC}_{x} \mathrm{~N}-(\mathrm{b})$ resulted in a more defective hexagonal structure, as assessed by XANES through the detection of $\mathrm{N}$ vacancies. The same result is

TABLE I. Energy position of B $\left(1 \mathrm{~s} \rightarrow \pi^{*}\right)$ XANES transitions assigned to different $s p^{2}$-boron bonding environments in $\mathrm{BC}_{\mathrm{x}} \mathrm{N}$ compounds.

\begin{tabular}{|c|c|c|c|}
\hline \multirow{2}{*}{$\begin{array}{l}s p^{2} \text {-boron } \\
\text { environment }\end{array}$} & \multirow{2}{*}{$\begin{array}{l}\text { Core-level shift } \\
\text { model }(\mathrm{eV})^{\mathrm{a}}\end{array}$} & \multicolumn{2}{|c|}{ Apparent peak position $(\mathrm{eV})^{\mathrm{b}}$} \\
\hline & & $\mathrm{BC}_{\mathrm{x}} \mathrm{N}-(\mathrm{a})$ & $\mathrm{BC}_{\mathrm{x}} \mathrm{N}-(\mathrm{b})$ \\
\hline $\mathrm{B}-\mathrm{C}_{3}$ & 189.9 & $190.1 \pm 0.1$ & $190.2 \pm 0.2$ \\
\hline $\mathrm{B}-\mathrm{C}_{2} \mathrm{~N}$ & 190.6 & $190.77 \pm 0.06$ & $190.9 \pm 0.1$ \\
\hline $\mathrm{B}-\mathrm{CN}_{2}$ & 191.2 & $191.38 \pm 0.04$ & $191.50 \pm 0.06$ \\
\hline $\mathrm{B}-\mathrm{OC}_{2}$ & 191.3 & & \\
\hline $\mathrm{B}-\mathrm{CNO}$ & 191.9 & $191.98 \pm 0.02$ & $192.13 \pm 0.03$ \\
\hline $\mathrm{B}-\mathrm{N}_{3}$ & 192.0 & & \\
\hline $\mathrm{B}-\mathrm{O}_{2} \mathrm{C}$ & 192.5 & $192.62 \pm 0.02$ & $192.74 \pm 0.03$ \\
\hline $\mathrm{B}-\mathrm{ON}_{2}$ & 192.6 & & \\
\hline $\mathrm{B}-\mathrm{O}_{2} \mathrm{~N}$ & 193.2 & $193.26 \pm 0.02$ & $193.36 \pm 0.03$ \\
\hline $\mathrm{B}-\mathrm{O}_{3}$ & 193.8 & $193.9 \pm 0.02$ & $194.08 \pm 0.05$ \\
\hline
\end{tabular}

${ }^{\mathrm{a}}$ From Ref. 32.

${ }^{\mathrm{b}}$ From deconvolution of B1s $\pi^{*}$ states in Fig. 3. derived by computing the XANES B:C:N:O ratios, with a higher content of oxygen in the (b) series compared to the (a) series, despite having similar $\mathrm{B}: \mathrm{C}: \mathrm{N}$ compositions. The oxygen content detected by XANES is represented in Figure 4 as a function of the $\mathrm{C}$ at. $\%$ for series (a) and (b) of samples. We observe that the $\mathrm{O}$ at. $\%$ decreases for both series with increasing $\mathrm{C}$ content. This is another key evidence to confirm that $\mathrm{O}$ atoms are primarily bound to $\mathrm{B}$ atoms, since the amount of $\mathrm{B}$ also decreases with the increase of $\mathrm{C}$ in the $\mathrm{BC}_{\mathrm{x}} \mathrm{N}$ films.

Importantly, the spectral lineshape of the O1s XANES remains similar within each series of samples, but is different for the two series, as represented in Figure 5. The $\mathrm{BC}_{\mathrm{x}} \mathrm{N}-(\mathrm{a})$ and $\mathrm{BC}_{\mathrm{x}} \mathrm{N}-(\mathrm{b}) \mathrm{O} 1 s$ XANES spectra correspond to the coatings with the highest XANES oxygen content (or lowest $\mathrm{C}$ at. \%). The reference spectra of $\mathrm{B}_{2} \mathrm{O}_{3}$ and $\mathrm{H}_{3} \mathrm{BO}_{3}$ have been also depicted for comparison purposes. On the one hand, the $\mathrm{O} 1 s$ photoabsorption edge of $\mathrm{BC}_{\mathrm{x}} \mathrm{N}-(\mathrm{a})$ samples is similar to $\mathrm{B}_{2} \mathrm{O}_{3}$ with $\pi$-bonded $\mathrm{B}-\mathrm{O}-\mathrm{B}$ oxygen atoms, except for a low intensity pre-edge peak between 531 and $533 \mathrm{eV}$ that can be attributed to a small amount of adsorbed molecular oxygen ${ }^{36}$ and/or $\mathrm{C}=\mathrm{O}$ groups. ${ }^{37}$ On the other hand, the O1s XANES spectra of $\mathrm{BC}_{\mathrm{x}} \mathrm{N}-(\mathrm{b})$ samples are similar to $\mathrm{H}_{3} \mathrm{BO}_{3}$, where the $\mathrm{B}-\mathrm{O}-\mathrm{H}$ oxygen atoms assume an $\mathrm{sp}^{3}$ hybridization and only $\sigma^{*}$ states are present. These results show that oxygen occupies $\mathrm{N}$ vacancies in the $\mathrm{BC}_{\mathrm{x}} \mathrm{N}$-(a) films as a bridging atom in the $\pi$-bonding structure of the compound. However, the $\mathrm{sp}^{3}$ oxygen observed for the $\mathrm{BC}_{\mathrm{x}} \mathrm{N}-(\mathrm{b})$ samples indicates a lower $\pi$-bonding continuity (Notice that the formation of an $\mathrm{sp}^{3} \mathrm{BC}_{\mathrm{x}} \mathrm{N}$ network is discarded from XANES, since neither $\mathrm{B}, \mathrm{C}$, nor $\mathrm{N}$ assume an $\mathrm{sp}^{3}$ hybridization). These observations are in agreement with the higher degree of disorder observed for the graphite-like bonding structure of series (b) compared to series (a). It should be mentioned here that, as it occurs for $\mathrm{B}_{2} \mathrm{O}_{3}$ and $\mathrm{H}_{3} \mathrm{BO}_{3},{ }^{38}$ the difference in $\mathrm{O}$ bonding environment detected for series (a) and (b) should not affect the corresponding B1s XANES features assigned to oxygen related $\mathrm{sp}^{2}$ boron bonding environments (see Table I). 
$B(1 s)$

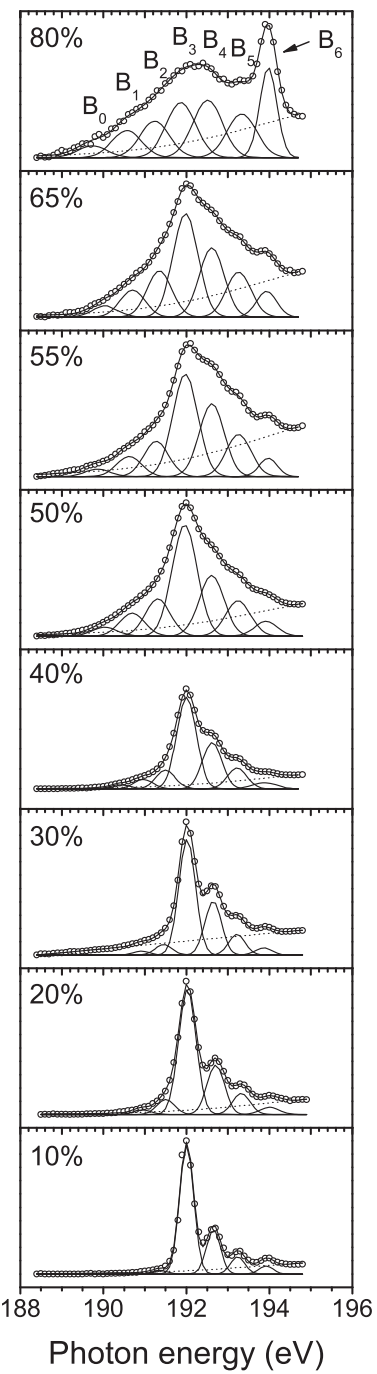

$B(1 s)$
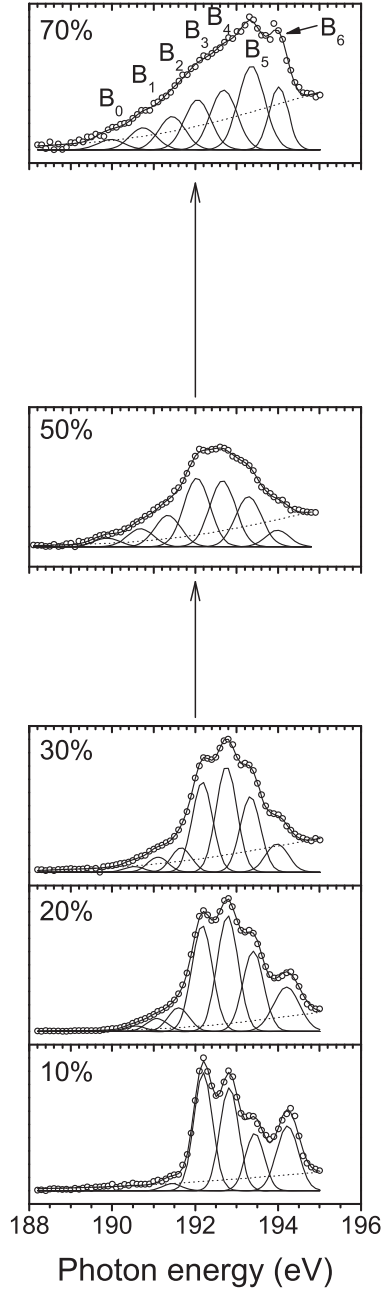

FIG. 3. Deconvolution (solid lines) of the B1s $\pi^{*}$ states of $\mathrm{BC}_{\mathrm{x}} \mathrm{N}-$ (a) (left panel) and $\mathrm{BC}_{\mathrm{x}} \mathrm{N}-(\mathrm{b})$ (right panel) compounds using up to 7 Gaussian curves corresponding to the $1 \mathrm{~s} \rightarrow \pi^{*}\left(B_{0}-B_{6}\right)$ transitions predicted by the core-level shift model. White dots represent the experimental XANES spectra.

\section{B. Carbon and nitrogen $1 s$ core-level edge}

The $\mathrm{C} 1 s$ core-level reveals important differences between $\mathrm{BC}_{x} \mathrm{~N}$-(a) and $\mathrm{BC}_{x} \mathrm{~N}$-(b) coatings. In the (a) series shown in Fig. 1, the C1s XANES spectra consist of at least 4 distinguishable $\mathrm{C} 1 s \pi^{*}$ features $\left(\mathrm{C}_{1}-\mathrm{C}_{4}\right)$ with an energy separation of $\sim 1.1 \mathrm{eV}$. Peaks $\mathrm{C}_{3}$ and $\mathrm{C}_{4}$ centred at $\sim 287.3 \mathrm{eV}$ and $\sim 288.4 \mathrm{eV}$, respectively, have been assigned to $\mathrm{C}$ in the hexagonal network of a ternary $\mathrm{BCN}$ phase. ${ }^{14}$ These peaks are well resolved and sharp for $\mathrm{C}$ contents of 10 at. \% approximately (i.e., $\sim \mathrm{BC}_{0.25} \mathrm{~N}$ ), but lose resolution for higher $\mathrm{C}$ contents. This is consistent with the amorphization of the graphitic $\mathrm{BC}_{x} \mathrm{~N}$ compounds upon carbon incorporation. Peaks $\mathrm{C}_{1}$ and $\mathrm{C}_{2}$ at $\sim 285.1 \mathrm{eV}$ and $\sim 286.2 \mathrm{eV}$ originate from defective or low coordination $\mathrm{C}$ atoms, as in $a$-C compounds. ${ }^{39}$

With regard to $\mathrm{BC}_{x} \mathrm{~N}-(\mathrm{b})$, their $\mathrm{C} 1 s$ XANES spectra exhibit a $\pi^{*}$ band with unresolved peaks. Nevertheless, four shoulders suggest the predominant presence of $\mathrm{C}_{1}-\mathrm{C}_{3}$ peaks and a new peak at $288.8 \mathrm{eV}$ that could originate from $\mathrm{C}=\mathrm{O}$ bonds. ${ }^{39}$ In this sense, peaks $\mathrm{C}_{1}$ and $\mathrm{C}_{2}$ associated to

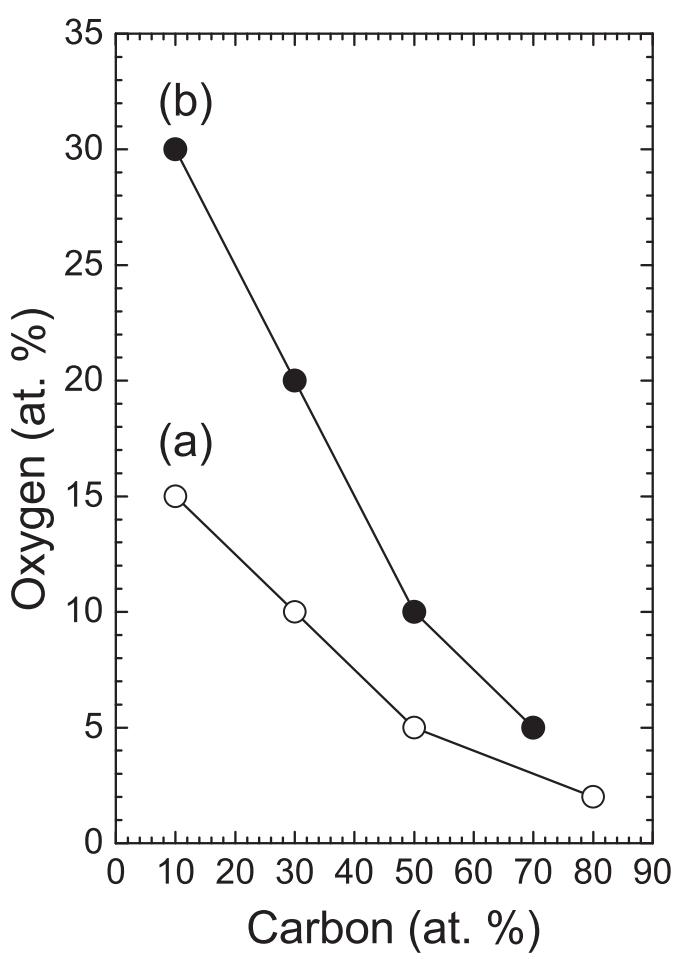

FIG. 4. Oxygen content determined by XANES for series (a) and (b) as a function of carbon concentration.

amorphous carbon environments are more intense in the $\mathrm{BC}_{x} \mathrm{~N}$-(b) series, indicating a higher structural disorder. This is clearly seen for $\mathrm{C}$ concentrations of 50 at. \% (i.e., $\mathrm{BC}_{2} \mathrm{~N}$ ) or higher, for which the C1s XANES spectra resemble those of an $a$-C material.

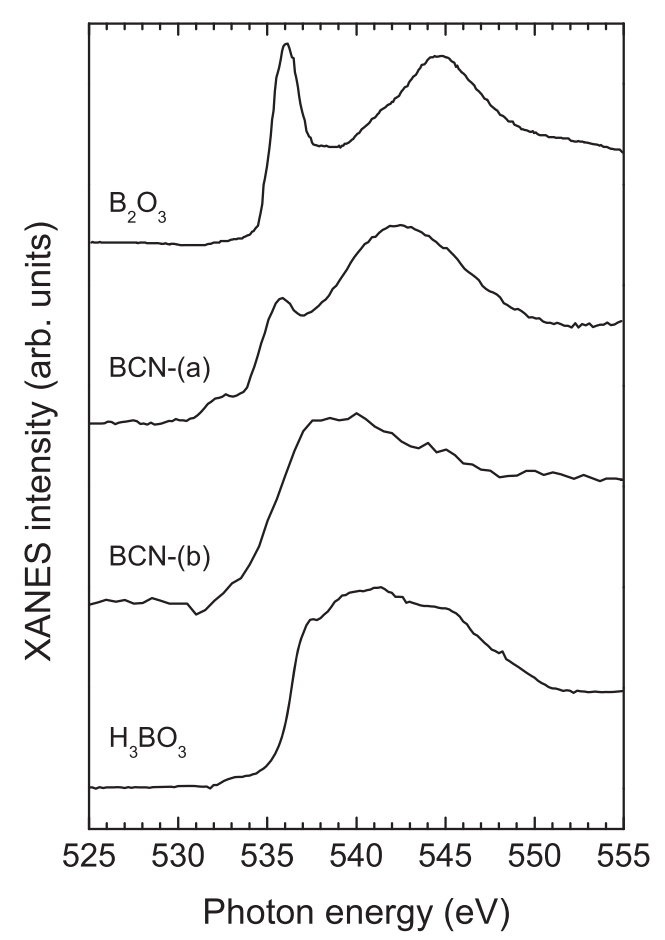

FIG. 5. Characteristic O1s XANES spectra of $\mathrm{BC}_{\mathrm{x}} \mathrm{N}$ thin films for series (a) and (b), together with the spectra from $\mathrm{B}_{2} \mathrm{O}_{3}$ and $\mathrm{H}_{3} \mathrm{BO}_{3}$ references. The spectra depicted correspond to the $\mathrm{BC}_{\mathrm{x}} \mathrm{N}$ coatings with the highest $\mathrm{O}$ at. $\%$ (or lowest $\mathrm{C}$ at. \%). 
The $\mathrm{C} 1 s$ XANES of both $\mathrm{BC}_{x} \mathrm{~N}$-(a) and $\mathrm{BC}_{x} \mathrm{~N}$-(b) present a comparable $\sigma^{*}$ edge shift from $289.7 \mathrm{eV}$ to $290.6 \mathrm{eV}$, approximately. By comparison with graphite and diamond, and as mentioned before for the B1s edge, this shift indicates an increase of the bond length with the $\mathrm{C}$ content consistent with the amorphization of the material with $\mathrm{C}$ incorporation.

With regards to the N1s edge, the sharper features corresponding to the $\mathrm{N} 1 s$ bonding environments in series (a) reflects a higher local order than series (b). Besides, the N1s $\sigma^{*}$ edge shifts with the $\mathrm{C}$ content for the sample set (a) from $405 \mathrm{eV}$ to $403 \mathrm{eV}$ approximately, but remains constant at $403.5 \mathrm{eV}$ for the (b) series (dashed lines in Figs. 1 and 2). The N1s XANES spectra of $\mathrm{BC}_{\mathrm{x}} \mathrm{N}-(\mathrm{a})$ exhibit up to four distinguishable $\pi^{*}$ peaks $\left(\mathrm{N}_{1}-\mathrm{N}_{4}\right)$, while two broad shoulders $\mathrm{A}$ and $\mathrm{B}$ are observed for $\mathrm{BCxN}-(\mathrm{b})$.

Peak $\mathrm{N}_{1}(\sim 398.7 \mathrm{eV})$ is assigned in asphaltenes ${ }^{40}$ and amorphous $\mathrm{CN}_{\mathrm{x}}{ }^{41}$ to pyridine-like bonding environments. In addition, peak $\mathrm{N}_{2}(399.7 \mathrm{eV})$ can be linked to either pyridinelike environments or $\mathrm{sp}^{1}$ nitrogen in $\mathrm{C} \equiv \mathrm{N}$, according to carbon nitride thin films ${ }^{42,43}$ and different carbonaceous compounds like acridines, carbazoles, and metalloporphyrins. ${ }^{40}$ Peak $\mathrm{N}_{3}(\sim 400.9 \mathrm{eV})$ can originate from either $h$-BN bonding environments or embedded nitrogen molecules in the film. This can be discerned by the shape and symmetry of the peak. The peak from molecular nitrogen is slightly asymmetric and contains very sharp features corresponding to molecular vibrations that can be resolved in high resolution spectra, whereas the $h$-BN excitonic peak is a broader feature. Finally, the broad $\mathrm{N}_{4}(\sim 401.9 \mathrm{eV})$ feature observed for 35 and $50 \mathrm{C}$ at. \%-i.e., $\mathrm{BCN}$ and $\mathrm{BC}_{2} \mathrm{~N}$ compositions, respectively-is ascribed here to pyridone-like environments. ${ }^{44}$

We observe that the $\mathrm{N} 1 s$ core-level edge of the $\mathrm{BC}_{\mathrm{x}} \mathrm{N}-(\mathrm{a})$ coatings is comparable to $h$-BN for low C contents (10 at. $\%)$. Besides, the intensity of peaks linked to pyridine-like and $\mathrm{C} \equiv \mathrm{N}$ bonds increases with the carbon concentration up to an 80 at. \% (i.e., $\mathrm{BC}_{8} \mathrm{~N}$ ). The latter spectrum exhibits an $\mathrm{N}_{3}$ peak whose line shape is characteristic of molecular nitrogen.

Concerning to $\mathrm{BC}_{\mathrm{x}} \mathrm{N}-(\mathrm{b})$ samples, and by comparison with series (a), peaks $A$ and $B$ may relate with broadened $\mathrm{N}_{1^{-}}$ $\mathrm{N}_{2}$ and $\mathrm{N}_{3}-\mathrm{N}_{4}$ states, respectively. Nevertheless, the lack of resolved features does not allow any definitive assignment of the $\mathrm{N}$ bonding environments. The $\mathrm{N} 1 s$ spectra are completely different in this case to $h$-BN, probably due to a highly defective structure, in agreement with the observations made at the B $1 s$ edge. Furthermore, the N1s $\pi^{*}$ intensity clearly decreases with $\mathrm{C}$ concentration, what implies a reduction of $\mathrm{sp}^{2}$ hybridized nitrogen atoms and an amorphization of the material.

\section{The B-C-N-V system and its mechanical performance}

As a whole, the results exposed demonstrate that there is a mixture of $\mathrm{B}, \mathrm{C}$, and $\mathrm{N}$ at atomic level, with new spectral features that cannot be assigned to any of the reference binary phases, as would correspond to formation of a ternary phase and not a mere mixing of segregated binary phases. Moreover, a clear amorphization effect due to $\mathrm{C}$ incorporation is detected by XANES by the broadening of the $\pi^{*}$ peaks and loss of resolved features in the $\pi^{*}$ bands. Both observations are consistent with our previous TEM study on these compounds. ${ }^{23}$

It is clear that the growing conditions affect enormously the structure of the $\mathrm{BC}_{\mathrm{x}} \mathrm{N}$ coating. Identical $\mathrm{B}: \mathrm{C}: \mathrm{N}$ ratios but different amount of nitrogen vacancy defects were obtained for sample sets (a) and (b). Thus, nitrogen vacancies (V) play a major role in the formation of ternary compounds with $\mathrm{BC}_{\mathrm{x}} \mathrm{N}$ composition, and could be considered as a fourth "element" in the final structure of the coating. Note that nitrogen vacancy defects are detected by XANES through an $\mathrm{O}$ decoration mechanism - due to air exposure -, which differs from series (a) to (b) as seen by analysis of the $\mathrm{O} 1 \mathrm{~s}$ XANES. This is just a surface effect, since measurements of the bulk composition by XEDS, ${ }^{15,23}$ TOF-ERDA, ${ }^{45}$ and EELS $^{23}$ have shown that the $\mathrm{O}$ concentration is never larger than 1 at. \% throughout the coating. In this sense, we should consider this BCN system as a B-C-N-V quaternary system in order to understand the possible final structure of boron carbonitride materials. A key question at this point is if, according to the oxygen decoration of the nitrogen vacancies, the material should be described as a B-C-N-O or a $\mathrm{B}-\mathrm{C}-\mathrm{N}-\mathrm{V}$. However, there is a significant discrepancy in the composition determined by surface sensitive (XANES) and bulk (XEDS) techniques, which suggests that oxygen decoration only takes place at the outermost part of the film, and that the bulk properties of the film (e.g., mechanical) would depend on the vacancy fraction and not on the oxygen content. Hence, the B-C-N-V description prevails.

It appears that the origin of the more defective $\mathrm{BC}_{\mathrm{x}} \mathrm{N}$ (b) structures is the higher ion-atom ratio employed during growth, which results in a higher transfer of energy and linear momentum and the associated effects of atomic displacements, defect creation, and amorphization of the structure.

Finally, we have studied the effect of the nitrogen vacancy- concentration on the mechanical performance of these $\mathrm{BC}_{\mathrm{x}} \mathrm{N}$ coatings. We have evaluated the wear resistance of the $\mathrm{BC}_{\mathrm{x}} \mathrm{N}$-(a) and (b) thin films with a "pin-on-disk" tribometer. A $3 \mathrm{~mm}$ diameter $\mathrm{WC} / \mathrm{Co}(6 \%)$ ball was used as counter material, applying a normal load of $3 \mathrm{~N}$ at a rotation speed of $375 \mathrm{rpm}$ and $1 \mathrm{~mm}$ rotation radius $(0.039 \mathrm{~m} / \mathrm{s}$ linear speed). All tests were done at a constant temperature of $23^{\circ} \mathrm{C}$ and $21 \%$ humidity. The wear resistance is defined here as the quotient between the distance covered by the tip over the $\mathrm{BC}_{\mathrm{x}} \mathrm{N}$ coating until its complete delamination and its total thickness, as measured with a profilometer. This parameter determines the average lifetime of the coating and includes the effects not only of abrasive wear but also of fatigue and fracture mechanisms. In this sense, it is more relevant from an application point of view than the usual wear coefficient which considers the loss of volume in the coating during abrasive wear. Figures 6(a) and 6(b) show the coefficient of friction (COF) and the wear resistance factor in $\log$ scale for series (a) and (b). The following thin film reference samples were also tested in the abovementioned conditions and included for comparison purposes: (1) CVD diamond, (2) ta-C $\left(80 \% \mathrm{sp}^{3}\right)$ deposited by filtered cathodic arc, (3) $\mathrm{CN}_{\mathrm{x}}$ prepared by IBAD, (4) evaporated $\mathrm{B}_{4} \mathrm{C}$ and $\mathrm{C}$. The COF slightly increases with the $\mathrm{C}$ content between $\sim 0.28-0.35$ and $\sim 0.22-0.28$ for the $\mathrm{BC}_{\mathrm{x}} \mathrm{N}-(\mathrm{a})$ and $\mathrm{BC}_{\mathrm{x}} \mathrm{N}-(\mathrm{b})$ 

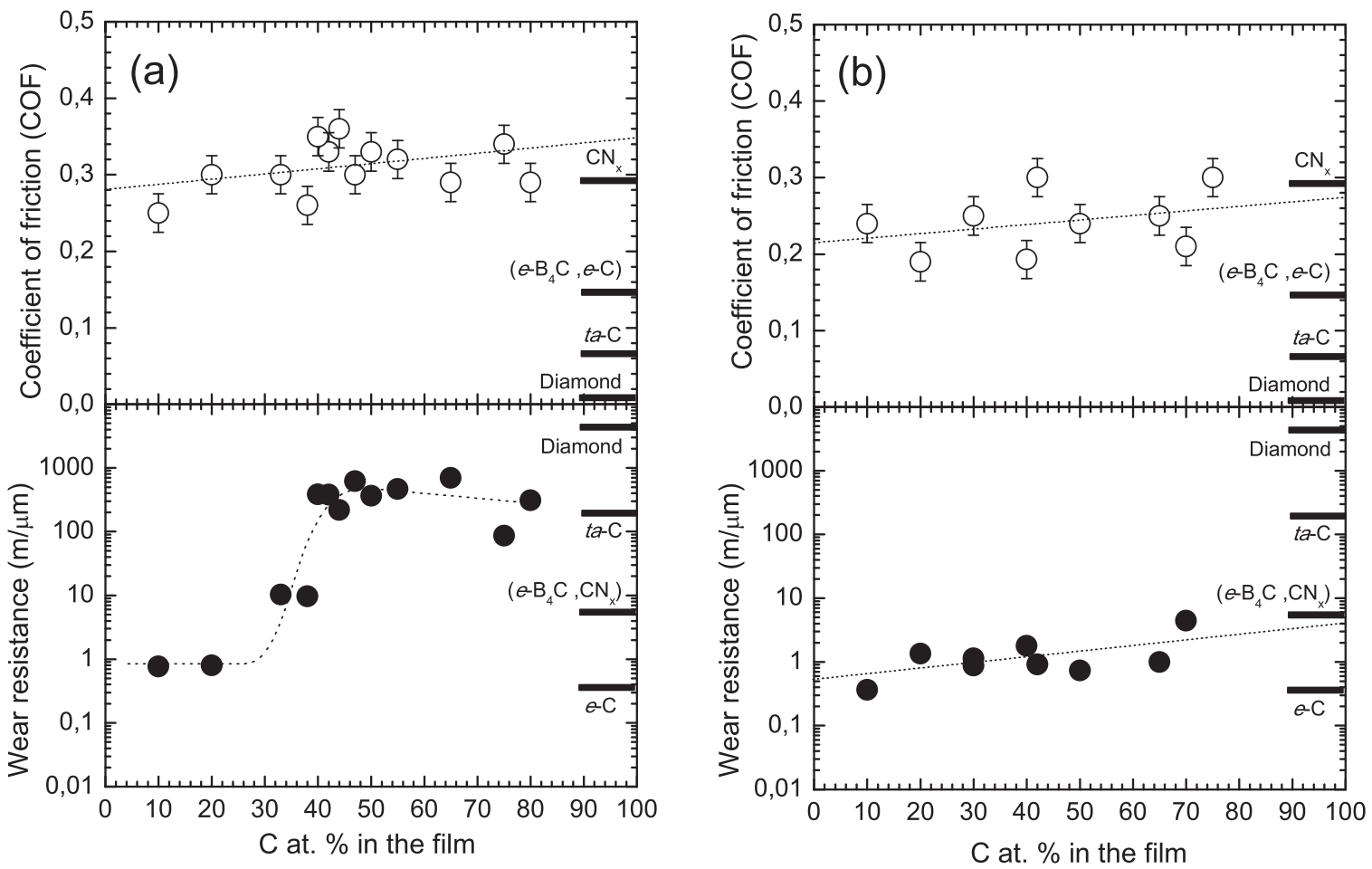

FIG. 6. Coefficient of friction and wear resistance of the $\mathrm{BC}_{\mathrm{x}} \mathrm{N}-(\mathrm{a})$ and $\mathrm{BC}_{\mathrm{x}} \mathrm{N}-(\mathrm{b})$ series as a function of the $\mathrm{C}$ at. \% in the films.

layers, respectively. These values are close to the graphitic $\mathrm{CN}_{\mathrm{x}}$ films deposited by IBAD. The wear resistance of the $\mathrm{BC}_{\mathrm{X}} \mathrm{N}$-(a) coatings shows a step-like transition from 1 to $500 \mathrm{~m} / \mu \mathrm{m}$ around 40 at. \% of C, approximately. The best wear resistance $(800 \mathrm{~m} / \mu \mathrm{m})$ is found for a $\mathrm{BC}_{4} \mathrm{~N}$ (a) type coating, which is higher than for the $t a-\mathrm{C}\left(80 \% \mathrm{sp}^{3}\right)$ reference film. $\mathrm{BC}_{\mathrm{x}} \mathrm{N}-(\mathrm{b})$ samples exhibit a low wear resistance about $1 \mathrm{~m} / \mu \mathrm{m}$ between 10 and 70 at. \% C. These observations are a clear evidence of the effect of vacancies in the structure of $\mathrm{BC}_{\mathrm{x}} \mathrm{N}$ compounds and their mechanical performance. It is noteworthy that $\mathrm{BC}_{\mathrm{x}} \mathrm{N}$ films with a dominant graphite-like bonding structure and $\mathrm{C}$ concentrations higher than 40 at. \% show a higher wear resistance than the ta-C $\left(80 \% \mathrm{sp}^{3}\right)$ reference. This behavior seems related to the amorphous structure of carbon-rich $\mathrm{BC}_{\mathrm{x}} \mathrm{N}$, where hexagonal planes cannot be identified by TEM, as shown in Ref. 43, despite a dominant three-fold coordination of the B, C, and $\mathrm{N}$ atoms. This amorphous structure may destroy the anisotropic mechanical properties of graphite like materials, weaker in the interplanar direction, yielding an isotropic high modulus material. A certain fraction of nitrogen vacancies seems to be optimal for the formation of this amorphous three-fold coordinated structure. However, too large a fraction of nitrogen vacancies, as in series (b) of samples, results in a less interconnected structure, with worse mechanical properties. Also, we recall that the wear resistance discussed here takes into account the whole performance of the coating, and is not only affected by the material hardness but also by its stability against delamination under the stresses induced by the loaded tip in relative motion. In this regard, it is worth reminding that ta-C coatings suffer from high internal stresses and adhesion problems that may result in delamination under harsh conditions.

\section{CONCLUSIONS}

Two series (a) and (b) of graphite-like $\mathrm{BC}_{\mathrm{x}} \mathrm{N}$ thin films were deposited by IBAD with different amount of $\mathrm{N}$-vacancy defects using different ion-atom impinging ratios. The effect of carbon incorporation and the formation of N-vacancy defects were analyzed by XANES. After exposure to air, vacancy sites at the surface are filled by oxygen atoms, which participate in $\pi$-bonding only for the less defective samples (series (a)). It was found that there is a strong influence of these $\mathrm{N}$-vacancy defects on the structure and mechanical performance of these materials. Whereas defective $\mathrm{BC}_{\mathrm{x}} \mathrm{N}$-(b) coatings exhibit a poor mechanical performance, the $\mathrm{BC}_{\mathrm{x}} \mathrm{N}$-(a) films present a marked improvement of the wear resistance for $\mathrm{C}$ concentrations higher than 40 at. \%., being superior to that of the $t a-\mathrm{C}$ $\left(80 \% \mathrm{sp}^{3}\right)$ reference film. The best mechanical performance was found for a composition near $\mathrm{BC}_{4} \mathrm{~N}$.

\section{ACKNOWLEDGMENTS}

We are indebted to A. Vollmer for her help at PM4 beamline (SURICAT endstation) of the Helmholtz-Zentrum Berlin - Electron storage ring BESSY II. The research leading to these results has received funding from the European Community's Seventh Framework Programme (FP7/20072013) under grant agreement n.226716. This work has been partially financed by the Spanish MICINN through project Consolider FUNCOAT CSD2008-0023, and project MOCASIN MAT2010-21070-C02-02. I. Caretti acknowledges support from CSIC through a JAE-Doc fellowship.

${ }^{1}$ Y. Yap, B-C-N Nanotubes and Related Nanostructures (Springer, Science+Business Media, New York, NY, 2009), Vol. 6 . 
${ }^{2}$ M. O. Watanabe, S. Itoh, K. Mizushima, and T. Sasaki, Appl. Phys. Lett. 68, 2962 (1996)

${ }^{3}$ D. Hegemann, R. Riedel, W. Dressler, C. Oehr, B. Schindler, and H. Brunner, Chem. Vap. Deposition 3, 257 (1997).

${ }^{4}$ M. Kawaguchi, Adv. Mater. 9, 615 (1997).

${ }^{5}$ J. Yu and E. G. Wang, Appl. Phys. Lett. 74, 2948 (1999).

${ }^{6}$ J. Yu, E. G. Wang, J. Ahn, S. F. Yoon, Q. Zhang, J. Cui, and M. B. Yu, J. Appl. Phys. 87, 4022 (2000).

${ }^{7}$ M. N. Oliveira and O. Conde, J. Mater. Res. 16, 734 (2001).

${ }^{8}$ T. Sugino, Y. Etou, T. Tai, and H. Mori, Appl. Phys. Lett. 80, 649 (2002).

${ }^{9}$ T. Sugiyama, T. Tai, and T. Sugino, Appl. Phys. Lett. 80, 4214 (2002).

${ }^{10}$ Z. X. Cao and H. Oechsner, J. Appl. Phys. 93, 1186 (2003).

${ }^{11}$ Z. J. Zhang, C. Kimura, and T. Sugino, J. Appl. Phys. 98, 036105 (2005).

${ }^{12}$ V. R. Shayapov, M. L. Kosinova, A. P. Smirnov, E. A. Maksimovskii, B. M. Ayupov, and Y. M. Rumyantsev, Inorg. Mater. 47, 262 (2011).

${ }^{13}$ L. Qin, J. Yu, S. Y. Kuang, C. Xiao, and X. D. Bai, Nanoscale 4, 120 (2012).

${ }^{14}$ R. Gago, I. Jimenez, J. M. Albella, and L. J. Terminello, Appl. Phys. Lett. 78, 3430 (2001)

${ }^{15}$ I. Caretti, I. Jimenez, R. Gago, D. Caceres, B. Abendroth, and J. M. Albella, Diamond Relat. Mater. 13, 1532 (2004).

${ }^{16}$ D. H. Kim, E. Byon, S. Lee, J. K. Kim, and H. Ruh, Thin Solid Films 447, 192 (2004).

${ }^{17}$ C. L. Li, B. R. Huang, S. Chattopadhyay, K. H. Chen, and L. C. Chen, Appl. Phys. Lett. 84, 2676 (2004).

${ }^{18}$ V. Linss, S. E. Rodil, P. Reinke, M. G. Garnier, P. Oelhafen, U. Kreissig, and F. Richter, Thin Solid Films 467, 76 (2004).

${ }^{19}$ M. F. Maitz, R. Gago, B. Abendroth, M. Camero, I. Caretti, and U. Kreissig, J. Biomed. Mater. Res., Part B: Appl. Biomater. 77B, 179 (2006).

${ }^{20}$ C. Morant, P. Prieto, J. Bareno, J. M. Sanz, and E. Elizalde, Thin Solid Films 515, 207 (2006).

${ }^{21}$ P.-C. Tsai, Surf. Coat. Technol. 201, 5108 (2007).

${ }^{22}$ I. Caretti, J. M. Albella, and I. Jimenez, Diamond Relat. Mater. 16, 63 (2007).

${ }^{23}$ I. Caretti, R. Torres, R. Gago, A. R. Landa-Canovas, and I. Jimenez, Chem. Mater. 22, 1949 (2010).

${ }^{24}$ M. F. Genisel, M. N. Uddin, Z. Say, M. Kulakci, R. Turan, O. Gulseren, and E. Bengu, J. Appl. Phys. 110, 074906 (2011).
${ }^{25}$ M. Watanabe, K. Mizushima, S. Itoh, and M. Mashita, "Semiconductor device using semiconductor BCN compounds," U.S. patent 5,747,118 (20 April 1999).

${ }^{26}$ D. Sauter, M. Weinmann, F. Berger, P. Lamparter, K. Muller, and F. Aldinger, Chem. Mater. 14, 2859 (2002).

${ }^{27}$ M. Krause, L. Bedel, A. Taupeau, U. Kreissig, F. Munnik, G. Abrasonis, A. Kolitsch, G. Radnoczi, Z. Czigany, and A. Vanhulsel, Thin Solid Films 518, 77 (2009).

${ }^{28}$ K. Yuge, Phys. Rev. B 79, 144109 (2009).

${ }^{29}$ J. R. Martins and H. Chacham, ACS Nano 5, 385 (2011).

${ }^{30}$ I. Jimenez, A. F. Jankowski, L. J. Terminello, D. G. J. Sutherland, J. A. Carlisle, G. L. Doll, W. M. Tong, D. K. Shuh, and F. J. Himpsel, Phys. Rev. B 55, 12025 (1997).

${ }^{31}$ M. Petravic, R. Peter, I. Kavre, L. H. Li, Y. Chen, L.-J. Fan, and Y.-W. Yang, Phys. Chem. Chem. Phys. 12, 15349 (2010).

${ }^{32}$ I. Caretti and I. Jimenez, J. Appl. Phys. 110, 023511 (2011).

${ }^{33}$ I. Caretti and I. Jimenez, Chem. Phys. Lett. 511, 235 (2011).

${ }^{34}$ I. Caretti, I. Jimenez, and J. M. Albella, Diamond Relat. Mater. 12, 1079 (2003).

${ }^{35}$ I. Caretti, N. Fanegas, Z. Martin, R. Torres, and I. Jimenez, J. Anal. At. Spectrom. 25, 150 (2010).

${ }^{36}$ J. G. Chen, Surf. Sci. Rep. 30, 1 (1997).

${ }^{37}$ D. W. Lee, L. De Los Santos V, J. W. Seo, L. L. Felix, A. Bustamante D, J. M. Cole, and C. H. W. Barnes, J. Phys. Chem. B 114, 5723 (2010).

${ }^{38}$ A. B. Preobrajenski, A. S. Vinogradov, E. Kleimenov, A. Knop-Gericke, S. A. Krasnikov, R. Szargan, and N. Martensson, Phys. Scr., T 115, 1071 (2005).

${ }^{39}$ R. Gago, I. Jimenez, J. M. Albella, A. Climent-Font, D. Caceres, I. Vergara, J. C. Banks, B. L. Doyle, and L. J. Terminello, J. Appl. Phys. 87, 8174 (2000).

${ }^{40}$ S. Mitra-Kirtley, O. C. Mullins, J. Van Elp, S. J. George, J. Chen, and S. P. Cramer, J. Am. Chem. Soc. 115, 252 (1993).

${ }^{41}$ G. Abrasonis, R. Gago, I. Jimenez, U. Kreissig, A. Kolitsch, and W. Moller, J. Appl. Phys. 98, 074907 (2005).

${ }^{42}$ M. Camero, J. G. Buijnsters, C. Gomez-Aleixandre, R. Gago, I. Caretti, and I. Jimenez, J. Appl. Phys. 101, 063515 (2007).

${ }^{43}$ R. Gago, I. Jiménez, J. Neidhardt, B. Abendroth, I. Caretti, L. Hultman, and W. Möller, Phys. Rev. B 71, 125414 (2005).

${ }^{44}$ Q. Zhu, S. L. Money, A. E. Russell, and K. M. Thomas, Langmuir 13, 2149 (1997).

${ }^{45}$ R. Gago, I. Jimenez, I. Garcia, and J. M. Albella, Vacuum 64, 199 (2002). 